\title{
Olfactory Identification Testing as a Predictor of the Development of Alzheimer's Dementia: A Systematic Review
}

\author{
Gordon H. Sun, MD; Cyrus A. Raji, MD, PhD; Mark P. MacEachern, MLIS; James F. Burke, MD, MS
}

\begin{abstract}
Objectives/Hypothesis: To evaluate the utility of olfactory identification tests as prognostic instruments for Alzheimer's dementia (AD).

Study Design: Systematic review.

Methods: In accordance with PRISMA guidelines, PubMed and Ovid MEDLINE, EMBASE, ISI Web of Science, PsycINFO, the Cochrane Database of Systematic Reviews, and the Cochrane Central Register of Controlled Trials were searched to determine the quality and quantity of longitudinal and cross-sectional research on this topic.

Results: Two prospective longitudinal cohort studies and 30 cross-sectional studies met inclusion criteria. The prospective longitudinal studies evaluated subjects with or without mild cognitive impairment (MCI) while also using olfactory identification testing as part of a neurocognitive evaluation. The first study reported an increased risk of later onset of AD in subjects with baseline hyposmia, whereas the second study suggested a possible relationship between decreased olfaction in participants with MCI and conversion to AD but was inconclusive due to low follow-up rates. Wide variability in the type of olfactory identification test used and the reporting of results precluded meta-analysis. The cross-sectional studies demonstrated a positive association between poorer performance on olfactory identification testing and AD.

Conclusions: Although there is evidence suggesting an association between decreased olfaction and AD, rigorously designed longitudinal cohort studies are necessary to clarify the value of olfactory identification testing in predicting the onset of AD.
\end{abstract}

Key Words: Alzheimer's disease, mild cognitive impairment, olfaction, smell test, screening, hyposmia, anosmia.

Level of Evidence: $2 a$.

Laryngoscope, 122:1455-1462, 2012

\section{INTRODUCTION}

Alzheimer's dementia (AD) is the most common cause of dementia, with an annual incidence of $1 \%$ in persons aged 60 to 70 years and $6 \%$ to $8 \%$ in those 85 years of age and older. ${ }^{1}$ The global prevalence of $\mathrm{AD}$ is estimated at 24 million and is expected to double every

From the Robert Wood Johnson Foundation Clinical Scholars (G.H.S., J.F.B.), University of Michigan, Ann Arbor, Michigan; VA Center for Clinical Management Research (G.H.S., J.F.B.), VA Ann Arbor Healthcare System, Ann Arbor, Michigan; Department of Otolaryngology-Head and Neck Surgery (G.H.S.), University of Michigan, Ann Arbor, Michigan; A. Alfred Taubman Health Sciences Library (M.P.M.), University of Michigan, Ann Arbor, Michigan; Department of Neurology (J.F.B.), University of Michigan, Ann Arbor, Michigan; Department of Radiology (C.A.R.), University of California-Los Angeles, Los Angeles, California, U.S.A. 28,2012 .

Editor's Note: This Manuscript was accepted for publication March

Additional Supporting Information may be found in the online version of this article.

Gordon Sun, MD and James Burke, MD are Robert Wood Johnson Foundation Clinical Scholars supported by the US Department of Veterans Affairs. The Robert Wood Johnson Foundation and the Department of Veterans Affairs were not directly involved in study design, data acquisition and interpretation, or manuscript preparation or review. Any opinions expressed herein do not necessarily reflect the opinions of the Robert Wood Johnson Foundation or the Department of Veterans Affairs. The authors have no other funding, financial relationships, or conflicts of interest to disclose.

Send correspondence to Gordon H. Sun, MD, 6312 Medical Science Building I, 1150 W. Medical Center Drive, SPC 5604, Ann Arbor, MI 48109-5604. E-mail: gordonsu@med.umich.edu

DOI: 10.1002/lary.23365
20 years through the year $2040{ }^{2}$ A simple, accurate, and inexpensive method of predicting the onset of $\mathrm{AD}$ consequently remains a valuable but elusive target for clinicians. Similarly, early identification of patients with $\mathrm{AD}$ is an important goal for researchers. Early identification may enrich clinical trials, which would be better served by targeting at-risk individuals early in the disease course or even in a presymptomatic stage.,

The association between $\mathrm{AD}$ and olfactory impairment has been previously reported. ${ }^{5-7}$ Accumulation of amyloid- $\beta$ plaques and tau protein neurofibrillary tangles throughout the olfactory nervous system appears to be the most highly supported hypothesis for the mechanism of action. ${ }^{8-11}$ Olfactory identification tests therefore are considered promising instruments for diagnosing $\mathrm{AD}$. A review of 27 clinical olfaction tests found excellent test-retest reliability scores in several major olfactory identification tests, such as the 40-item University of Pennsylvania Smell Identification Test (UPSIT) $(r=$ $0.94)$ and the three-item Pocket Smell Test (PST) $(r=$ 0.80). ${ }^{12}$ The ability of olfactory identification tests to distinguish between true and false hyposmic patients is less clearly established. However, the UPSIT can distinguish between actual anosmic patients and malingerers, ${ }^{13,14}$ whereas the PST has a $99 \%$ sensitivity and $40 \%$ specificity for detecting anosmia. ${ }^{15}$ Other advantages to olfactory identification testing include effectiveness in discriminating among varying levels of olfactory function, low cost, and ease of administration 
compared to other instruments such as olfactory threshold testing. ${ }^{12,16,17}$

We sought to determine the predictive value of olfactory identification tests in the development of $\mathrm{AD}$. First, we identified the evidence that olfactory identification tests predict conversion to $\mathrm{AD}$ by obtaining all longitudinal studies on olfactory identification testing as a method of detecting incipient $\mathrm{AD}$ among adult subjects with and without baseline mild cognitive impairment (MCI). As a secondary objective, we characterized the association between abnormal olfaction as identified by olfactory identification testing and the diagnosis of $\mathrm{AD}$ by identifying all cross-sectional studies that analyzed associations between olfactory dysfunction and $\mathrm{AD}$ using olfactory identification tests.

\section{MATERIALS AND METHODS}

\section{Search Strategy}

We conducted this review using a prespecified protocol, based on the 2009 Preferred Reporting Items for Systematic Reviews and Meta-Analyses (PRISMA) guidelines. ${ }^{18}$ An experienced health sciences librarian then conducted a search of PubMed and Ovid MEDLINE, EMBASE, ISI Web of Science, PsycINFO, Cochrane Database of Systematic Reviews, and Cochrane Central Register of Controlled Trials in January 2012. We also reviewed reference lists of review articles and other relevant publications, including manuscripts accessed through the Cochrane Database of Systematic Reviews, for additional studies. Conference proceedings and abstracts, databases of gray literature or unpublished data, and non-English publications were not considered for review due to limited resources. A full description of the search strategy and complete list of the search terms and limits used in each database are included in the online Supplementary Appendix. Citations were imported into EndNote (Thomson Reuters, New York, NY). The combined database searches yielded 2,067 citations, of which 893 duplicate records were removed prior to formal review.

\section{Study Selection}

Two authors reviewed all articles for inclusion, with disagreements being resolved by discussion between the reviewers. Our primary objective was to describe the predictive value of olfactory identification testing for conversion to $\mathrm{AD}$ by reviewing prospective clinical trials and longitudinal observational studies. Longitudinal studies were considered more important in this review than cross-sectional analyses because the former track changes in patient populations over time and represent the gold standard study design to assess the value of prognostic information, whereas cross-sectional analyses demonstrate simple associations and are more susceptible to confounding. ${ }^{19}$ Inclusion criteria included the following: initial trial population including adult patients with baseline normal cognition and/or $\mathrm{MCI}$, longitudinal development of $\mathrm{AD}$ as an outcome, and olfactory identification testing as part of the evaluation of study participants at both enrollment and follow-up. If the target article did not explicitly mention either $\mathrm{AD}$ or olfactory identification testing, or was unclear regarding $\mathrm{AD}$ or olfaction data, it was excluded. Exclusion criteria included the following: use of olfactory threshold, memory, or recognition testing without olfactory identification testing; retrospective study designs; publications such as editorials or letters; and study of exclusively non-Alzheimer's causes of dementia, such as Parkinson's disease (PD) or vascular dementia. Articles available before 1984 were excluded because the first olfactory identification test (UPSIT) was not published until that year. Studies with overlapping or duplicate cohorts were excluded.

A secondary analysis was performed to quantify studies that evaluated the association between $\mathrm{AD}$ and impaired olfactory identification testing. All cross-sectional studies that involved olfactory identification testing and compared normal subjects or subjects with MCI with subjects diagnosed with $\mathrm{AD}$ were considered eligible. Inclusion criteria were similar, though clearly longitudinal development of $\mathrm{AD}$ as an outcome was no longer applicable. Exclusion criteria were the same as those used for longitudinal studies.

\section{Data Extraction and Quality Assessment}

The article reviewers independently extracted the following data: number of participants, study recruitment setting, type of olfactory identification test and olfaction data, and inclusion of other neurologic disorders if applicable. For longitudinal studies, cohort age, gender, and country of origin, duration of follow-up, and definitions for $\mathrm{MCI}, \mathrm{AD}$, and olfactory dysfunction were also acquired, and the articles themselves were summarized. The reviewers independently assessed methodological quality of longitudinal studies using Quality Assessment Tool for Diagnostic Accuracy Studies (QUADAS) criteria. ${ }^{20}$ Dissimilarities in data extraction and QUADAS scoring were resolved by discussion between the two reviewers.

\section{RESULTS}

The original database literature search yielded 1,174 potential articles (Fig. 1). After the initial round of screening, 125 articles were obtained for full-text review, including 10 articles found by manual reference search. During full-text screening, 93 additional articles were disqualified. Five studies ${ }^{21-25}$ were found to have cohorts identical to or substantially overlapping the cohorts of the two longitudinal studies that ultimately qualified for complete analysis.

\section{Summary of Longitudinal Studies}

Two longitudinal cohort studies met all inclusion and exclusion criteria for our primary analysis (Table I). A total of 217 individuals participated in these studies, of which 147 were followed longitudinally. Due to the small number of studies and significant heterogeneity in study design and reported outcome measures, metaanalysis was not feasible. Table II includes the olfactory identification test and the definitions of MCI, AD, and olfactory dysfunction used in each study.

Devanand et al. ${ }^{26}$ designed a prospective cohort study of 148 subjects with MCI to investigate the role of several baseline diagnostic instruments in predicting conversion to $\mathrm{AD}$. Inclusion criteria included age between 41 and 85 years, history of cognitive impairment, and MiniMental State Examination (MMSE) score $\geq 22 / 30$. Exclusion criteria included substance abuse or history of stroke or other neurological or psychiatric diseases.

One hundred twenty-six subjects completed the 3 year follow-up and were grouped into AD-converters (33/ $126,26.1 \%)$ and nonconverters (93/126, 73.8\%) for analysis. Baseline assessment revealed no statistically 


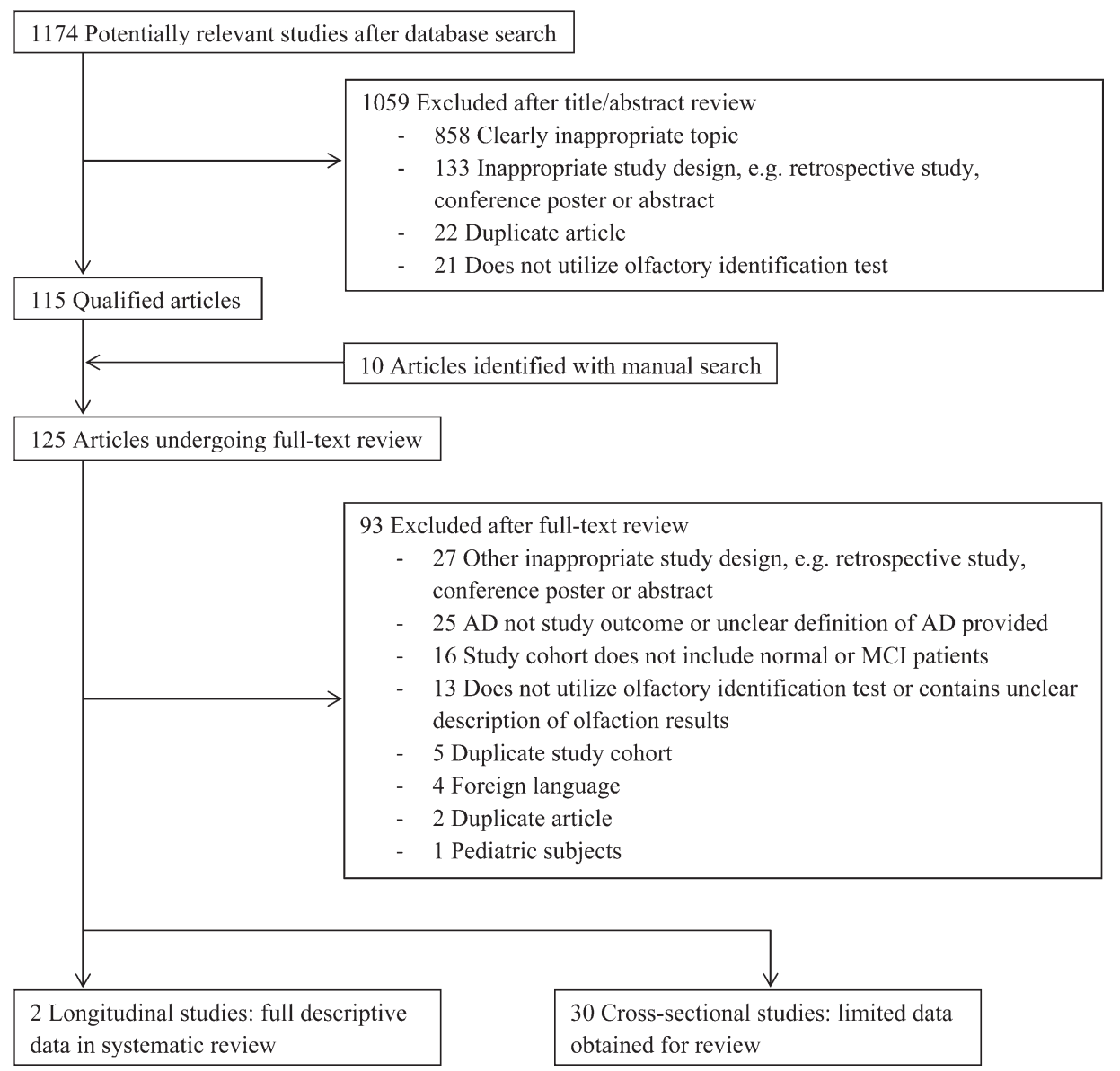

Fig. 1. Study selection flowchart. $A D=$ Alzheimer's disease; $M C l=$ mild cognitive impairment.

significant differences between these subgroups in age, education, or MMSE scores. After controlling for potential predictors of conversion to $\mathrm{AD}$, baseline UPSIT scores were significantly lower among AD-converters compared to nonconverters (25.8 vs. 33.2, $P<.0001)$. The authors estimated that UPSIT testing had a sensitivity of $48.5 \%$ for predicting the development of $\mathrm{AD}$.

Bahar-Fuchs et al. ${ }^{27}$ recruited participants in part from a longitudinal single-center cohort study investigating brain amyloid positron-emission tomography (PET) imaging. ${ }^{28}$ In addition to the 69 subjects drawn from the PET cohort, three additional subjects were recruited through other methods. Exclusion criteria included chronic medical conditions affecting olfactory function or a medical history suggestive of a non-AD etiology to cognitive dysfunction, such as previous significant head injury. Olfactory identification testing was conducted primarily using a subset of six items from the BSIT. Using the control group's median olfactory identification score of 4.5 as the cutoff point for normal olfaction, 23 $(92 \%)$ MCI patients had olfactory identification impairment at baseline.

Twenty-one subjects without baseline $\mathrm{AD}$ (eight controls and 13 subjects with amnestic MCI [aMCI]) completed full olfactory testing 12 months after enrollment. Six out of $13(46.1 \%)$ aMCI patients met formal criteria for $\mathrm{AD}$. The conversion rate of participants with normal cognition to $\mathrm{AD}$ was not reported. Among the subjects with baseline aMCI, AD converters had worse olfactory identification scores compared to nonconverters (2.33 vs. 3.44 ), although this difference was not statistically significant. Six of the 7 nonconverting aMCI subjects exhibited significantly lower total olfactory scores than the control group $(P<.001)$. The proportion of normal controls who did not notice a subjective decline in olfactory identification did not differ significantly from participants with baseline aMCI or AD who also did not notice such decline.

\section{Summary of Cross-Sectional Studies}

Thirty remaining articles featured cross-sectional study designs comparing subjects with or without baseline MCI to subjects with preexisting $\mathrm{AD}$ (Table III). One of these studies $^{29}$ did follow a large community cohort of elderly individuals over time, but only presented olfaction data at follow-up and not at enrollment. All 30 studies found that participants with baseline $\mathrm{AD}$ had statistically worse olfactory identification scores (i.e., worse sense of smell) compared to subjects who were cognitively normal or had baseline MCI. Twenty studies controlled for age or demonstrated no statistically significant age differences between normal and $\mathrm{AD}$ subjects on post hoc analysis, whereas two studies 
TABLE I.

Demographics, Recruitment Strategy, Follow-up, and Methodological Quality of Longitudinal Studies Using Olfactory Identification Testing as Prognostic Instruments for Alzheimer's Disease.

\begin{tabular}{|c|c|c|c|c|c|c|c|c|}
\hline Study (Year) & $\begin{array}{l}\text { No. of } \\
\text { Starting } \\
\text { Patients }\end{array}$ & $\begin{array}{l}\text { No. of } \\
\text { Patients } \\
\text { Completing } \\
\text { Follow-up }\end{array}$ & Age, yr & Male Gender & Country & Recruitment Strategy & $\begin{array}{l}\text { Time to } \\
\text { Follow-up, } \\
\text { mo }\end{array}$ & $\begin{array}{l}\text { QUADAS } \\
\text { Score }\end{array}$ \\
\hline $\begin{array}{l}\text { Bahar-Fuchs } \\
(2011)^{27}\end{array}$ & $\begin{array}{l}22 \text { (normal), } \\
25 \text { (MCl), } \\
25 \text { (AD) }\end{array}$ & $\begin{array}{l}8 \text { (normal), } \\
13(\mathrm{MCl})^{*}\end{array}$ & $\begin{array}{l}71.7 \text { (normal), } \\
74.4 \text { (MCl) }\end{array}$ & $\begin{array}{c}45.5 \% \text { (normal), } \\
64 \%(\mathrm{MCl})\end{array}$ & Australia & $\begin{array}{l}\text { Direct recruitment from } \\
\text { longitudinal PiB-PET } \\
\text { study }(69 / 72 \text { total } \\
\text { subjects) }\end{array}$ & 12 & 9 \\
\hline $\begin{array}{l}\text { Devanand } \\
(2008)^{26}\end{array}$ & $148(\mathrm{MCl})$ & 126 & 67.2 & $45 \%$ & United States & $\begin{array}{l}\text { Recruitment from a } \\
\text { university-based } \\
\text { memory disorders clinic }\end{array}$ & 36 & 9 \\
\hline
\end{tabular}

Maximum possible QUADAS score in this review is 14.

*Reasons for limited follow-up cohort (e.g., study dropout) were not published.

QUADAS = Quality Assessment Tool for Diagnostic Accuracy Studies; $\mathrm{MCl}=$ mild cognitive impairment; AD = Alzheimer's dementia; PiB = Pittsburgh Compound B; PET = positron-emission tomography.

included controls of both older and younger age. Ten studies controlled for gender, nine for educational level, and two for smoking status.

Nine studies concurrently studied subjects with disorders such as PD and vascular dementia. Thirteen different olfactory identification tests were utilized. The UPSIT was the most commonly used test, but because numerical data were presented in a wide variety of methods, and in many cases were not presented at all, meta-analysis of studies using the UPSIT alone was not considered practical.

\section{DISCUSSION}

Our systematic review found a large body of evidence establishing an association between hyposmia and AD. However, for olfactory identification testing to have clinical or research utility, it must do more than merely be associated with $\mathrm{AD}$; it must be a useful predictor of conversion to dementia. We identified no randomized controlled trials addressing this question and only two prospective longitudinal studies that suggested that hyposmia had only moderately predictive value. Devanand et al. did describe an increased risk of developing $\mathrm{AD}$ with baseline hyposmia, but the study by BaharFuchs et al. failed to find a statistically significant relationship.

The most straightforward explanation for the association between $\mathrm{AD}$ and olfactory dysfunction is that $\mathrm{AD}$ causes olfactory dysfunction. However, this is not the only possibility. First, the association may be confounded by other variables that predict both $\mathrm{AD}$ and hyposmia. For example, both $\mathrm{AD}$ and hyposmia (in cognitively normal individuals) increase in frequency with age. ${ }^{30}$ Although it is plausible that hyposmia may well be related to abnormal amyloid- $\beta$ plaque and tau protein buildup in the olfactory system seen in $\mathrm{AD}$, this relationship could be confounded by other physiologic changes seen in the elderly, such as decreased hydration and mucous secretion within the olfactory cleft, thinning of the olfactory mucosa, and prolonged exposure to toxic environmental agents. ${ }^{30}$ The extensive cross-sectional body of research is particularly susceptible to confounding as one-third of these studies failed to control for even the most obvious confounding variable: age. Additionally, as with all nonexperimental designs, they are susceptible to confounding by unmeasured variables. Second, because $\mathrm{AD}$ can be challenging to distinguish from other neurodegenerative disorders that have been associated with olfactory dysfunction, such as $\mathrm{PD}$, it is possible that misdiagnosis may misleadingly give rise to an association between olfactory dysfunction and $\mathrm{AD} .^{31,32}$

A limitation of this review was the exclusion of studies that did not use $\mathrm{AD}$ as a primary outcome and which instead employed specific neuropsychological tests as surrogate outcome measures of cognitive impairment. However, these excluded studies were all cross-sectional

TABLE II.

Neuropathologic Definitions and Olfactory Identification Tests Used in Qualified Longitudinal Studies.

\begin{tabular}{|c|c|c|c|c|}
\hline Study (Year) & Definition of $\mathrm{MCl}$ & Definition of $A D$ & $\begin{array}{l}\text { Olfactory } \\
\text { Identification } \\
\text { Test }\end{array}$ & $\begin{array}{l}\text { Definition of } \\
\text { Olfactory } \\
\text { Dysfunction }\end{array}$ \\
\hline Bahar-Fuchs $(2011)^{27}$ & $\begin{array}{l}\text { International Working Group on } \\
\mathrm{MCl} \text { consensus criteria } \\
\text { (Petersen criteria) }\end{array}$ & $\begin{array}{l}\text { Probable AD by } \\
\text { NINCDS-ADRDA } \\
\text { criteria }\end{array}$ & $\begin{array}{l}\text { BSIT (full set and } \\
6-\text { question } \\
\text { subset) }\end{array}$ & $\begin{array}{l}<4.5 / 10 \text { (median score } \\
\text { of control group) }\end{array}$ \\
\hline Devanand $(2008)^{26}$ & $\begin{array}{l}\text { Two-person consensus diagnosis } \\
\text { using clinical, neuropsychological, } \\
\text { laboratory, and imaging data* }\end{array}$ & $\begin{array}{l}\text { Possible or probable } \\
\text { AD by NINCDS-ADRDA } \\
\text { criteria }\end{array}$ & UPSIT & $<32 / 40$ \\
\hline
\end{tabular}

*Study began before $\mathrm{MCl}$ criteria were published.

$\mathrm{MCl}=$ mild cognitive impairment, $\mathrm{AD}=$ Alzheimer's disease, NINCDS-ADRDA = National Institute of Neurological and Communicative Disorders and Stroke-Alzheimer's Disease and Related Disorders Association, BSIT = Brief Smell Identification Test, UPSIT = University of Pennsylvania Smell Identification Test. 


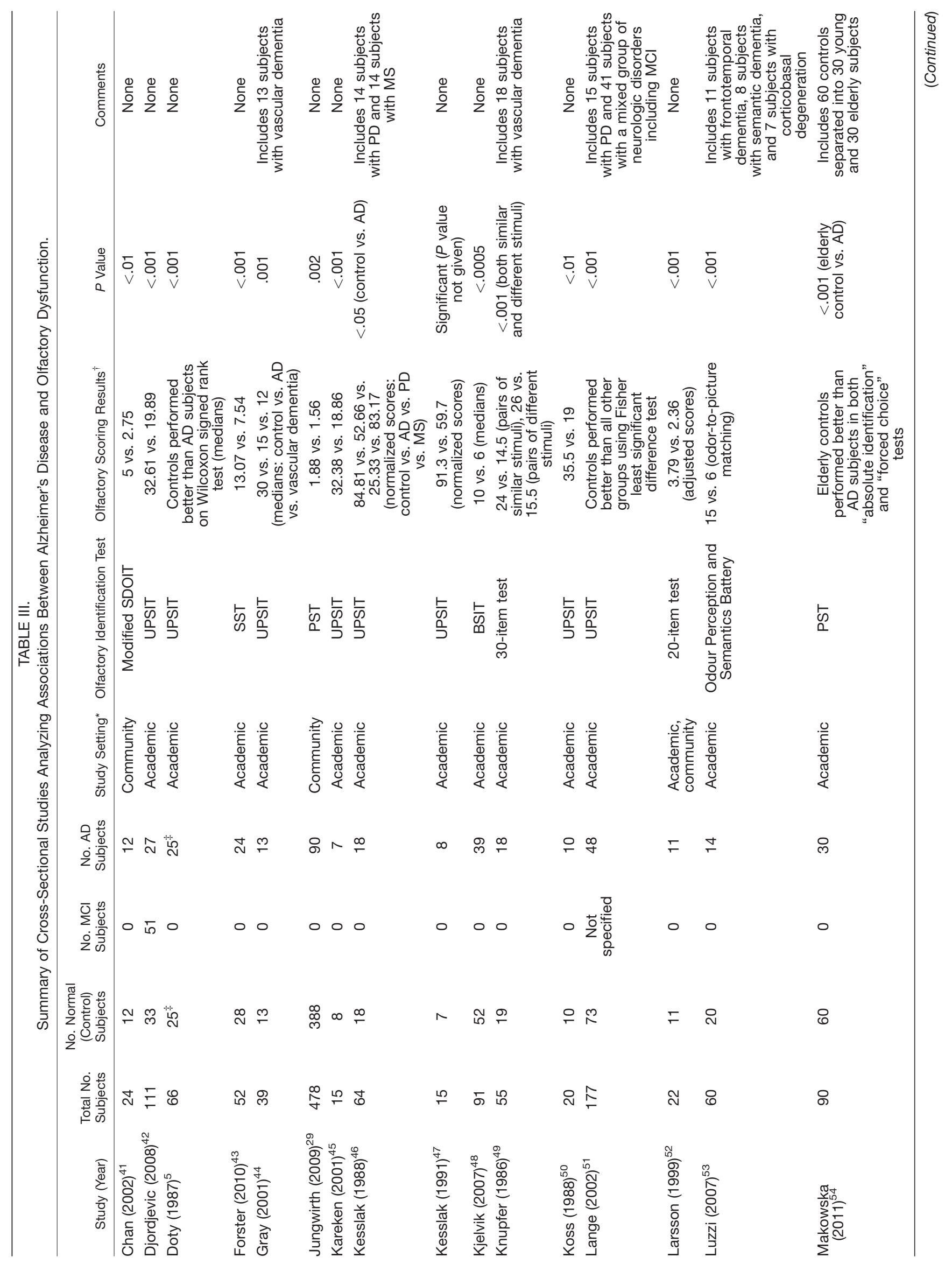




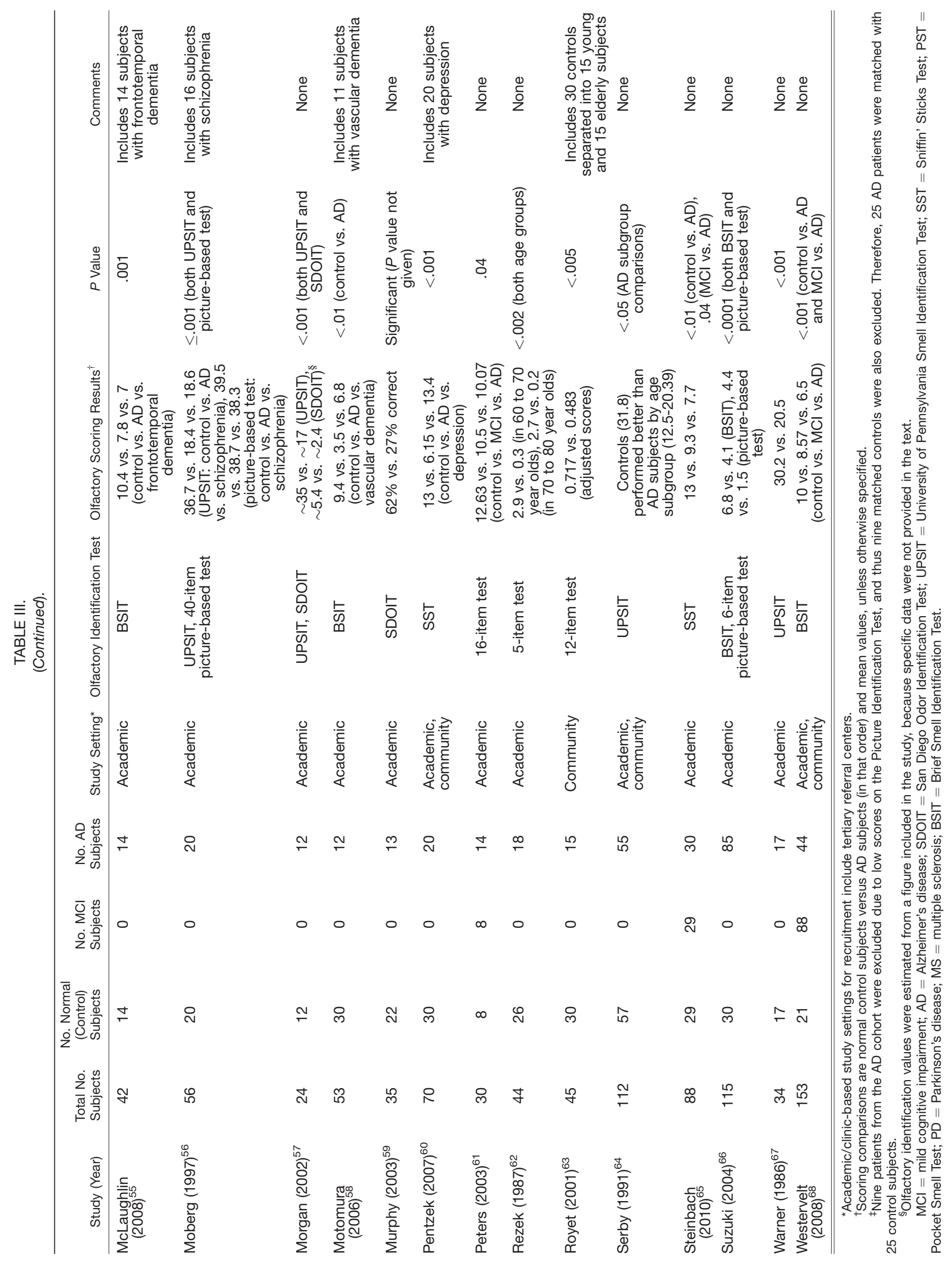


in design. We did not locate any longitudinal studies that used surrogate neuropsychological tests as outcome measures for $\mathrm{AD}$ but met all other inclusion criteria. Several other excluded reports used dementia as a primary outcome, without explicitly defining Alzheimer'stype dementia. Dementia is a generic term that encompasses many other neurologic disorders that share multiple symptoms with $\mathrm{AD}$. A wide range of neurodegenerative disorders (e.g., PD, depression) and other neurologic conditions (e.g., head trauma) are also associated with hyposmia. ${ }^{7,32-35}$ Without specifying whether a given study included $\mathrm{AD}$ as a specific subtype, the association between $\mathrm{AD}$ and decreased olfaction would have been artificially inflated. Inclusion of all dementia subtypes or other neurodegenerative disorders would be beyond the scope of this project. Another limitation is the exclusion of gray literature resources, which could result in research being overlooked. However, we also recognize that such studies, including conference presentations and abstracts, might have incomplete data and not be in definitive form. We also believed it unlikely that a high-quality longitudinal study would not have remained unpublished; the several abstracts we incidentally encountered during the systematic search described cross-sectional studies, and many of these were later recognized as having been formally published and would have met our exclusion criteria for duplicate work.

The demand for a rapid, inexpensive, and valid method of screening at-risk populations for $\mathrm{AD}$ has become increasingly urgent, as large-scale multicenter projects such as the Alzheimer's Disease Neuroimaging Initiative progress forward ${ }^{36}$ and interest in olfactory testing crosses over to the lay public. ${ }^{37,38}$ Cross-sectional evidence corroborates the association between hyposmia and $\mathrm{AD}$ but does little to validate the use of olfactory identification as a clinical screening or prognostic instrument. Longitudinal studies of multiethnic, multiregional community-based cohorts of elderly individuals with well-characterized cognitive profiles and olfactory data at baseline and at multiple points over time would be a better approach, a sentiment shared by other authors. ${ }^{11,39}$ Incorporating the new National Institute of Aging-Alzheimer's Association diagnostic criteria, ${ }^{40}$ including the use of cerebrospinal fluid, magnetic resonance imaging, and/or PET biomarkers at follow-up, would not only sharpen outcome measures but may offer dementia subtype-specific implications on olfactory identification testing and its relationship to other emerging biomarkers. Finally, the use of controls or age- and gender-matched validated normative data as a comparison standard when scoring olfactory identification tests is more likely to yield clinically useful outcomes.

\section{CONCLUSION}

Olfactory identification testing is a promising, lowcost, efficient screening tool for AD. The current body of cross-sectional studies indicates a potential association between $\mathrm{AD}$ and olfactory dysfunction, although using olfactory data alone to distinguish between $\mathrm{AD}$ and other neurocognitive disorders may not be possible. Furthermore, the predictive value of olfactory dysfunction in the development of $\mathrm{AD}$ is uncertain given the paucity of longitudinal data. Additional well-designed longitudinal cohort studies would greatly clarify the role of olfactory identification testing in the neurocognitive evaluation of individuals at risk for $\mathrm{AD}$.

\section{Acknowledgments}

The authors would like to thank Charles P. Kishman, MSLS, and Edith Starbuck, MLS, for their assistance with compiling the preliminary search term list; Vikas Kotagal, $\mathrm{MD}$, for assistance with data collection and critical manuscript reviews; and D. P. Devanand, MD, and Susanne Jungwirth, $\mathrm{PhD}$, for their prompt communication regarding their research projects.

\section{BIBLIOGRAPHY}

1. Mayeux R. Clinical practice. Early Alzheimer's disease. $N$ Engl J Med 2010;362:2194-2201.

2. Reitz C, Brayne C, Mayeux R. Epidemiology of Alzheimer disease. Nat Rev Neurol 2011;7:137-152.

3. Aisen PS, Andrieu S, Sampaio C, et al. Report of the task force on designing clinical trials in early (predementia) AD. Neurology 2011;76: $280-286$.

4. Getsios D, Blume S, Ishak KJ, Maclaine G, Hernandez L. An economic evaluation of early assessment for Alzheimer's disease in the United Kingdom. Alzheimers Dement 2012;8:22-30.

5. Doty RL, Reyes PF, Gregor T. Presence of both odor identification and detection deficits in Alzheimer's disease. Brain Res Bull 1987;18: $597-600$.

6. Murphy C, Gilmore MM, Seery CS, Salmon DP, Lasker BR. Olfactory thresholds are associated with degree of dementia in Alzheimer's disease. Neurobiol Aging 1990;11:465-469.

7. Schiffman SS. Taste and smell losses in normal aging and disease. JAMA 1997;278:1357-1362.

8. Arnold SE, Lee EB, Moberg PJ, et al. Olfactory epithelium amyloid-beta and paired helical filament-tau pathology in Alzheimer disease. Ann Neurol 2010;67:462-469.

9. Attems J, Jellinger KA. Olfactory tau pathology in Alzheimer disease and mild cognitive impairment. Clin Neuropathol 2006;25:265-271.

10. Attems J, Lintner F, Jellinger KA. Olfactory involvement in aging and Alzheimer's disease: an autopsy study. J Alzheimers Dis 2005;7:149-157; discussion $173-180$.

11. Wesson DW, Wilson DA, Nixon RA. Should olfactory dysfunction be used as a biomarker of Alzheimer's disease? Expert Rev Neurother 2010;10: 633-635.

12. Doty RL. Office procedures for quantitative assessment of olfactory function. Am J Rhinol 2007;21:460-473.

13. Doty RL, Shaman P, Dann M. Development of the University of Pennsylvania Smell Identification Test: a standardized microencapsulated test of olfactory function. Physiol Behav 1984;32:489-502.

14. Doty RL, Shaman P, Kimmelman CP, Dann MS. University of Pennsylvania Smell Identification Test: a rapid quantitative olfactory function test for the clinic. Laryngoscope 1984;94:176-178.

15. Jackman AH, Doty RL. Utility of a three-item smell identification test in detecting olfactory dysfunction. Laryngoscope 2005;115:2209-2212.

16. Doty RL. Olfactory dysfunction and its measurement in the clinic and workplace. Int Arch Occup Environ Health 2006;79:268-282.

17. Negoias S, Troeger C, Rombaux P, Halewyck S, Hummel T. Number of descriptors in cued odor identification tests. Arch Otolaryngol Head Neck Surg 2010;136:296-300.

18. Moher D, Liberati A, Tetzlaff J, Altman DG. Preferred reporting items for systematic reviews and meta-analyses: the PRISMA statement. Ann Intern Med 2009;151:264-269,W264.

19. Johnson SL. Research and statistics: a question of time: cross-sectional versus longitudinal study designs. Pediatr Rev 2010;31:250-251.

20. Whiting P, Rutjes AW, Reitsma JB, Bossuyt PM, Kleijnen J. The development of QUADAS: a tool for the quality assessment of studies of diagnostic accuracy included in systematic reviews. BMC Med Res Methodol 2003;3:25.

21. Bahar-Fuchs A, Chetelat G, Villemagne VL, et al. Olfactory deficits and amyloid-beta burden in Alzheimer's disease, mild cognitive impairment, and healthy aging: a PiB PET study. J Alzheimers Dis 2010;22: 1081-1087.

22. Bahar-Fuchs A, Moss S, Rowe C, Savage G. Olfactory performance in AD, aMCI, and healthy ageing: a unirhinal approach. Chem Senses 2010;35: $855-862$. 
23. Bahar-Fuchs A, Moss S, Rowe C, Savage G. Can I smell gas (or is it lilac)? Olfactory semantic deficits in mild cognitive impairment and Alzheimer's disease. Chemosens Percept 2010;3:118-128.

24. Devanand DP, Michaels-Marston KS, Liu X, et al. Olfactory deficits in patients with mild cognitive impairment predict Alzheimer's disease at follow-up. Am J Psychiatry 2000;157:1399-1405.

25. Tabert MH, Liu X, Doty RL, et al. A 10-item smell identification scale related to risk for Alzheimer's disease. Ann Neurol 2005;58: $155-160$

26. Devanand DP, Liu X, Tabert MH, et al. Combining early markers strongly predicts conversion from mild cognitive impairment to Alzheimer's disease. Biol Psychiatry 2008;64:871-879.

27. Bahar-Fuchs A, Moss S, Rowe C, Savage G. Awareness of olfactory deficit in healthy aging, amnestic mild cognitive impairment and Alzheimer's disease. Int Psychogeriatr 2011;23:1097-1106.

28. Rowe $\mathrm{CC}, \mathrm{Ng} \mathrm{S}$, Ackermann U, et al. Imaging beta-amyloid burden in aging and dementia. Neurology 2007:68:1718-1725.

29. Jungwirth S, Zehetmayer S, Bauer P, Weissgram S, Tragl KH, Fischer P. Screening for Alzheimer's dementia at age 78 with short psychometric instruments. Int Psychogeriatr 2009;21:548-559.

30. Lafreniere D, Mann N. Anosmia: loss of smell in the elderly. Otolaryngol Clin North Am 2009;42:123-131,x.

31. Knopman DS, DeKosky ST, Cummings JL, et al. Practice parameter: diagnosis of dementia (an evidence-based review). Report of the Quality Standards Subcommittee of the American Academy of Neurology. Neurology 2001;56:1143-1153.

32. Mesholam RI, Moberg PJ, Mahr RN, Doty RL. Olfaction in neurodegenerative disease: a meta-analysis of olfactory functioning in Alzheimer's and Parkinson's diseases. Arch Neurol 1998;55:84-90.

33. Corwin J. Olfactory identification in hemodialysis: acute and chronic effects on discrimination and response bias. Neuropsychologia 1989;27: $513-522$

34. Lutterotti A, Vedovello M, Reindl M, et al Olfactory threshold is impaired in early, active multiple sclerosis. Mult Scler 2011:17:964-969.

35. Negoias S, Croy I, Gerber J, et al. Reduced olfactory bulb volume and olfactory sensitivity in patients with acute major depression. Neuroscience 2010;169:415-421.

36. Aisen PS, Petersen RC, Donohue MC, et al Clinical Core of the Alzheimer's Disease Neuroimaging Initiative: progress and plans. Alzheimers Dement 2010;6:239-246.

37. Rubin R. Scientists sniff at home Alzheimer's test. May 9, 2001. Available at: http://www.usatoday.com/news/health/2001-05-10-alzheimers-test.htm. Accessed March 22, 2012.

38. The Dr. Oz Show. Alzheimer's Smell Test. May 31, 2011. Available at: http://www.doctoroz.com/videos/alzheimers-smell-test. Accessed March 22,2012

39. Caroli A, Frisoni GB. The dynamics of Alzheimer's disease biomarkers in the Alzheimer's Disease Neuroimaging Initiative cohort. Neurobiol Asing 2010:31:1263-1274.

40. Jack CR Jr, Albert MS, Knopman DS, et al. Introduction to the recommendations from the National Institute on Aging-Alzheimer's Association workgroups on diagnostic guidelines for Alzheimer's disease. Alzheimer Dement 2011;7:257-262.

41. Chan A, Tam J, Murphy C, Chiu H, Lam L. Utility of olfactory identification test for diagnosing Chinese patients with Alzheimer's disease. $J$ Clin Exp Neuropsychol 2002;24:251-259.

42. Djordjevic J, Jones-Gotman M, De Sousa K, Chertkow H. Olfaction in patients with mild cognitive impairment and Alzheimer's disease. Neurobiol Aging 2008;29:693-706.

43. Forster S, Vaitl A, Teipel SJ, et al. Functional representation of olfactory impairment in early Alzheimer's disease. J Alzheimers Dis 2010;22 $581-591$.

44. Gray AJ, Staples V, Murren K, Dhariwal A, Bentham P. Olfactory identification is impaired in clinic-based patients with vascular dementia and senile dementia of Alzheimer type. Int J Geriatr Psychiatry 2001;16: $513-517$
45. Kareken DA, Doty RL, Moberg PJ, et al. Olfactory-evoked regional cerebral blood flow in Alzheimer's disease. Neuropsychology 2001:15: $18-29$.

46. Kesslak JP, Cotman CW, Chui HC, et al. Olfactory tests as possible probes for detecting and monitoring Alzheimer's disease. Neurobiol Aging 1988; 9:399-403

47. Kesslak JP, Nalcioglu O, Cotman CW. Quantification of magnetic resonance scans for hippocampal and parahippocampal atrophy in Alzheimer's disease. Neurology 1991;41:51-54.

48. Kjelvik G, Sando SB, Aasly J, Engedal KA, White LR. Use of the brief smell identification test for olfactory deficit in a Norwegian population with Alzheimer's disease. Int J Geriatr Psychiatry 2007;22:1020-1024.

49. Knupfer L. Differences in olfactory test performance between normal aged, Alzheimer and vascular type dementia individuals. Int $J$ Geriatr Psychiatry 1986;1:3-14.

50. Koss E, Weiffenbach JM, Haxby JV, Friedland RP. Olfactory detection and identification performance are dissociated in early Alzheimer's disease. Neurology 1988;38:1228-1232.

51. Lange R, Donathan CL, Hughes LF. Assessing olfactory abilities with the University of Pennsylvania smell identification test: a Rasch scaling approach. J Alzheimers Dis 2002;4:77-91.

52. Larsson M, Semb H, Winblad B, Amberla K, Wahlund LO, Backman L. Odor identification in normal aging and early Alzheimer's disease: effects of retrieval support. Neuropsychology 1999;13:47-53.

53. Luzzi S, Snowden JS, Neary D, Coccia M, Provinciali L, Lambon Ralph MA. Distinct patterns of olfactory impairment in Alzheimer's disease, semantic dementia, frontotemporal dementia, and corticobasal degeneration. Neuropsychologia 2007;45:1823-1831.

54. Makowska I, Kloszewska I, Grabowska A, Szatkowska I, Rymarczyk K. Olfactory deficits in normal aging and Alzheimer's disease in the polish elderly population. Arch Clin Neuropsychol 2011;26:270-279.

55. McLaughlin NC, Westervelt HJ. Odor identification deficits in frontotemporal dementia: a preliminary study. Arch Clin Neuropsychol 2008;23: $119-123$.

56. Moberg PJ, Doty RL, Mahr RN, et al. Olfactory identification in elderly schizophrenia and Alzheimer's disease. Neurobiol Aging 1997;18:163-167.

57. Morgan CD, Murphy C. Olfactory event-related potentials in Alzheimer's disease. J Int Neuropsychol Soc 2002;8:753-763.

58. Motomura N, Tomota Y. Olfactory dysfunction in dementia of Alzheimer's type and vascular dementia. Psychogeriatrics 2006;6:19-20.

59. Murphy C, Jernigan TL, Fennema-Notestine C. Left hippocampal volume loss in Alzheimer's disease is reflected in performance on odor identification: A structural MRI study. J Int Neuropsychol Soc 2003;9:459-471.

60. Pentzek M, Grass-Kapanke B, Ihl R. Odor identification in Alzheimer's disease and depression. Aging Clin Exp Res 2007;19:255-258.

61. Peters JM, Hummel T, Kratzsch T, Lotsch J, Skarke C, Frolich L. Olfactory function in mild cognitive impairment and Alzheimer's disease: An investigation using psychophysical and electrophysiological techniques. Am J Psychiatry 2003;160:1995-2002.

62. Rezek DL. Olfactory deficits as a neurologic sign in dementia of the Alzheimer type. Arch Neurol 1987;44:1030-1032

63. Royet JP, Croisile B, Williamson-Vasta R, Hibert O, Serclerat D, Guerin J. Rating of different olfactory judgements in Alzheimer's disease. Chem Senses 2001;26:409-417.

64. Serby M, Larson P, Kalkstein D. The nature and course of olfactory deficits in Alzheimer's disease. Am J Psychiatry 1991;148:357-360.

65. Steinbach S, Hundt W, Vaitl A, et al. Taste in mild cognitive impairment and Alzheimer's disease. $J$ Neurol 2010;257:238-246.

66. Suzuki Y, Yamamoto S, Umegaki H, et al. Smell identification test as an indicator for cognitive impairment in Alzheimer's disease. Int $J$ Geriatr Psychiatry 2004;19:727-733.

67. Warner MD, Peabody CA, Flattery JJ, Tinklenberg JR. Olfactory deficits and Alzheimer's disease. Biol Psychiatry 1986;21:116-118.

68. Westervelt HJ, Bruce JM, Coon WG, Tremont G. Odor identification in mild cognitive impairment subtypes. J Clin Exp Neuropsychol 2008;30: $151-156$. 